\title{
Failure Mechanism and Minimum Safe Thickness of Grouting Reinforcement Ring in Tunnels Excavated by Borehole Blasting
}

\author{
Chunquan Dai*, Yunlong Lv \\ College of Civil Engineering and Architecture, Shandong University of Science and Technology, Qingdao 266590, China
}

Corresponding Author Email: dcqwin@sdust.edu.cn

https://doi.org/10.18280/ti-ijes.630114

Received: 21 January 2019

Accepted: 18 March 2019

\section{Keywords:}

borehole blasting, grouting reinforcement $(G R)$, reinforcement ring instability, minimum safe thickness (MST)

\begin{abstract}
During tunneling by borehole blasting, the grouting reinforcement (GR) ring may lose stability, leading to water and mud inrush. To prevent these disasters, this paper establishes a GR model for tunnels excavated by borehole blasting, after summing up the relevant theories. Meanwhile, the failure mechanisms of the GR layer were deliberated under different geological conditions, from the perspective of mechanics, revealing that the instability hinges on the quality of the GR layer and the external water pressure. On this basis, the instability modes were classified into two categories: hydraulic fracturing and overall instability. After that, the minimum safe thickness (MST) formulas were derived for the GR layer of different failure modes, according to the elastic beam elastic model and the theories on blasting excavation disturbance belt and hydraulic fracturing belt. Finally, the proposed formulas were proved rational and universal through a FLAC ${ }^{3 \mathrm{D}}$ numerical simulation on Xiamen Xiang'an Subsea Tunnel, Fujian, China.
\end{abstract}

\section{INTRODUCTION}

During tunnel construction, geological disasters like water and mud inrush and collapse are extremely to occur in places with unfavorable geological conditions, such as weak formation, fractured zone and karst area [1-2]. To ensure the safety of tunnel construction, the grouting technique has been widely adopted to reinforce the unfavorable geological structures [3-4].

For most tunnels, the thickness of grouting reinforcement (GR) is mainly determined through theoretical analysis, engineering analogy and numerical simulation [7-9]. In most cases, the effect of excavation disturbance is not considered. However, most tunnels in hard rocks are excavated by borehole blasting. During construction, the blasting vibration may induce the propagation of cracks, lowering the integrity of the surrounding rock, and even lead to crack penetration and coalescence, which preludes disasters like instability and water and mud inrush [10]. Therefore, it is highly necessary to examine the dynamic response of the surrounding rock in the tunnel under blasting load. So far, the dynamic response of the surrounding rock has been analyzed for tunnel construction with borehole blasting under different construction conditions and engineering backgrounds [21-22]. However, there is rarely any report on the minimum safe thickness (MST) of GR for the rock mass under blasting load.

After summing up tunnel engineering examples, this paper establishes a model on the GR layer, analyses the failure mechanisms of the GR layer rock masses under borehole blasting, and divides the failure mechanisms (instability modes) into different categories. On this basis, mechanical models were constructed according to different instability modes, and the MST of the grouted rock mass was computed. Finally, the MST formula was verified through a FLAC3D numerical simulation of the service tunnel of Xiamen Xiang'an Subsea Tunnel, Fujian, China.

\section{INSTABILITY MODES}

\subsection{GR model}

To enhance the overall stability of the tunnel, the surrounding rock should be pre-grouted before the tunnel passes through unfavorable geological sections. Then, the grouting fluid can seal up the fractures and cement the rock mass, creating a barrier against the penetration of external water and the pore water inside the rock mass [11].

According to the theory on GR ring closure, there should be an airtight grouting curtain around the tunnel after the GR, leaving no large area un-grouted. The GR layer should exist as a closed, dense wall around the tunnel, making the latter strong and waterproof [12]. The longitudinal and horizontal profiles of the GR layer are presented in Figures 1 and 2 below.

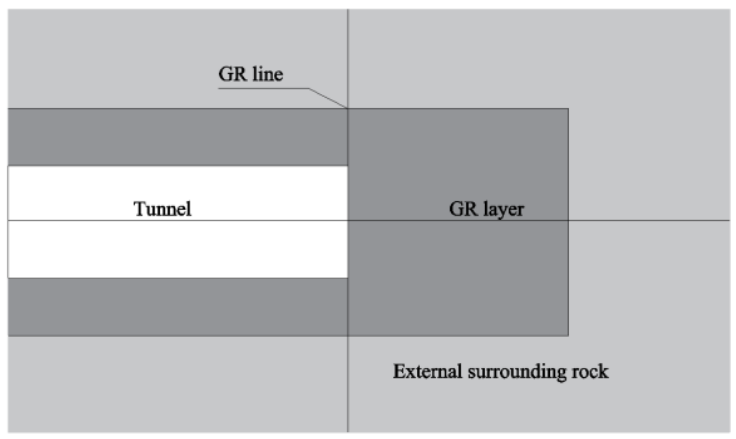

Figure 1. The longitudinal profile of the GR layer model 


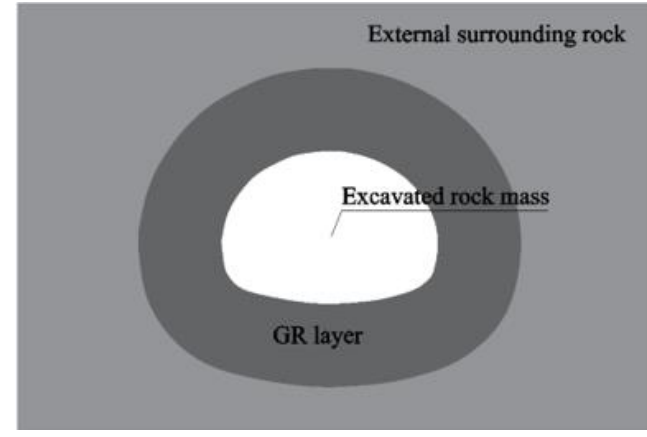

Figure 2. The horizontal profile of the GR layer model

\subsection{Instability modes under borehole blasting}

Under borehole blasting, the damages of the GR layer surrounding rock continues to accumulate until the failure occurs. The failure mechanism can be understood as the dynamic evolution of the microcracks inside the rock. During tunnel construction, the blasting causes the redistribution of the stress on the surrounding rock. The transient unloading of excavation, coupled with the blasting load, creates a certain range of plastic damages and even cracks. In this case, the stress field and the seepage field of the surrounding rock change more violently, making the surrounding rock less strong and sowing the seeds for water and mud inrush. Through the above analysis, it is confirmed that the GR layer instability is triggered by three necessary conditions, namely, the water-bearing structure with energy storage, the energy release condition and the construction disturbance [8]. Besides, the GR layer quality and external water pressure were considered the key causes of tunnel instability.

If the GR layer is not thoroughly grouted, some cracks will remain in local areas of the surrounding rock. These cracks will develop under the rock-water pressure and the dynamic load disturbance, leading to the hydraulic fracturing of the surrounding rock. Then, the external cracks may extend inwards, and even connect with the plastic damage zone formed in excavation under borehole blasting. The rock mass will become more permeable, enhancing the seepage effect. The seeping water in the cracks of the surrounding rock will soften the rock mass, and wash the filling in the cracks. If not strong enough to withstand the seepage force, the filling will be washed away, pushing up the hydraulic conductivity on crack surface. In this way, the neighboring cracks are more likely to connect to each other. The crack opening will increase as the rock on the crack surface is peeled off under the high water pressure [13].

When the GR layer surrounding rock is under a small water pressure, the cracks developed in the rock mass cannot propagate by the water pressure. In this case, the GR layer's resistance to deformation and instability hinges on the overall strength of the structure. The surrounding rock will loss stability when the GR layer is not thick enough to withstand the external load. In light of the above failure conditions, the failure modes of GR layer surrounding rock were divided into hydraulic fracturing failure and overall instability failure.

(1) Hydraulic fracturing

When the hydraulic fracture of the GR layer occurs, the overall structure of the surrounding rock often does not reach the yield strength. The damage is directly caused by the local stress concentration. Under the disturbance of blasting excavation, the inherent cracks of GR layer surrounding rock are activated and expanded. Next, the cracks in the rock mass further expands and even connects with each other under the action of high waterhead. Thus, the seepage channels in the rock mass are altered, increasing the permeability. The original channels gradually widen due to the washing and scouring of water. Disasters like water inrush and instability will ensue. The hydraulic fracturing failure is illustrated in Figure 3 below.

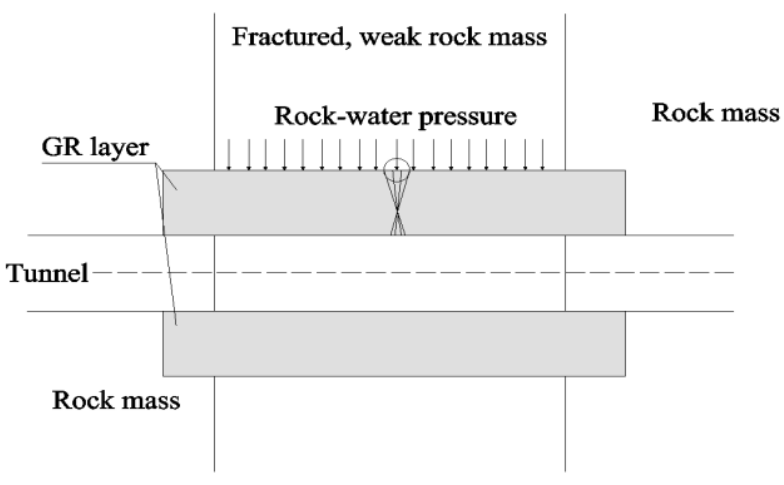

Figure 3. The hydraulic fracturing failure

Hydraulic fracturing damage mostly takes places when the construction reaches the deep rock mass, which is under high water pressure. For shallow underground projects, the crack water pressure is not sufficient to induce hydraulic fracturing of the GR layer surrounding rock, despite large water supply from channels formed through karstification and so on. In general, hydraulic fracturing failure is featured by large flow, high waterhead and suddenness [19].

For example, the diversion tunnel of Jinping Hydropower Station (Phase II) is buried at about 1,500 2,500 $\mathrm{m}$. The water pressure is as high as $10 \mathrm{MP}$ in certain places. As a result, several hydraulic fracturing failures were observed during the tunnel construction. The water outlets of the tunnel are generally scattered, and concentrated in some local areas. The damage is particularly severe on the left wall and the left roof, with a water inflow of $10 \mathrm{~L} / \mathrm{s}$. All these reflect the features of hydraulic fracturing failure.

(2) Overall instability

Compared with the hydraulic fracturing damage, the compressive stress generated by the filling water in the unfavorable geological structure and the self-weight of the rock mass are key drivers of surrounding rock instability in the GR layer. The surrounding rock will be crushed when the compressive stress is greater than the strength of the GR layer [3]. The overall instability failure is explained in Figure 4 below.

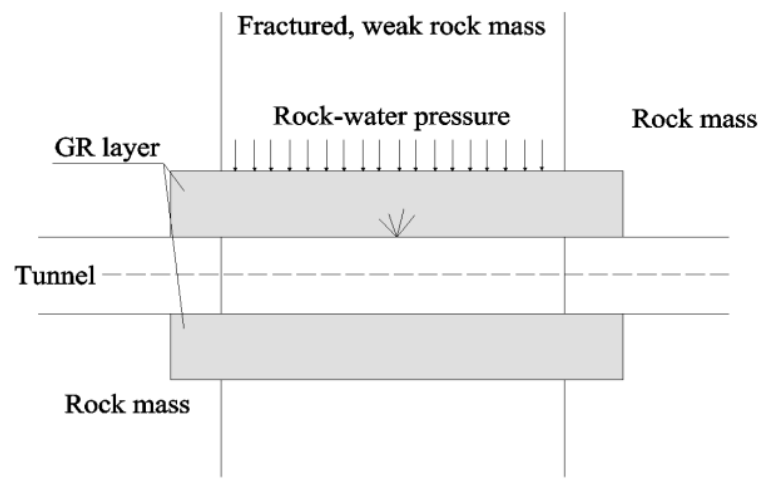

Figure 4. The overall instability failure 
Taking Qingdao Metro Line 1 for instance, the metro tunnel was not effectively grouted when passing through the fault fracture zone. The original GR layer could not withstand the rock-water pressure from the fractured zone above, not to mention the huge disturbance from blasting excavation. Eventually, the GR layer was yielded and sheared, leading to water and mud inrush accidents [14].

\section{MECHANICAL MODELS}

The preceding section has examined the hydrogeological conditions of the unfavorable geological sections, and analyzed the instability modes of the GR layer surrounding rock under different conditions. On this basis, two mechanical models were set up for the hydraulic fracturing failure and overall instability failure, respectively, of the GR layer surrounding rock, and used to compute the safe range of the GR layer, laying a theoretical basis for subsequent construction.

\subsection{Hydraulic fracturing failure}

Under the high waterhead, the GR layer rock layer was divided into blasting excavation disturbance belt and hydraulic fracturing belt (hereinafter referred to as the "two belts") (Figure 5). Comparing the karst water pressure and the critical water pressure of rock mass shear failure, the GR layer's MST under the construction with borehole blasting can be derived as:

$L=L_{c}+L_{w}$

where $L_{c}$ is the thickness of the blasting excavation disturbance belt; $L_{w}$ is the thickness of the hydraulic fracturing belt.

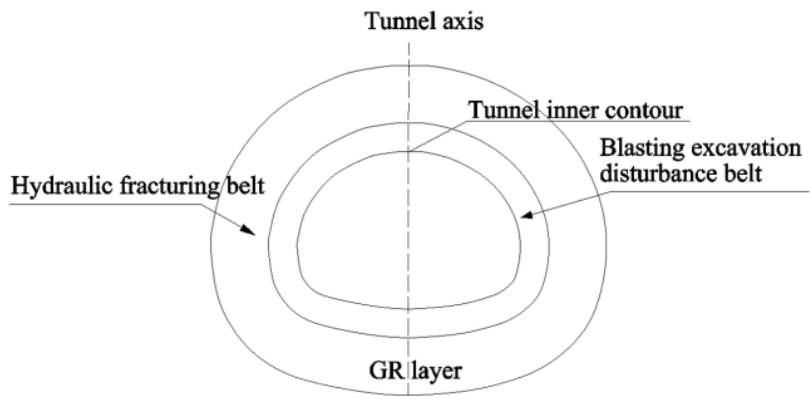

Figure 5. The two belts of hydraulic fracturing failure

The cracks of the rock mass in the GR ring are initialized under tensile or compressive shearing. The cracks will continue to propagate until the stress intensity factor is equal to the dynamic fracture toughness of the cracks [15]. Once the cracks stop expanding, the distance from the cracks to the tunnel edge is the thickness of the blasting excavation disturbance belt. Moreover, it is assumed that this belt has no water blocking effect.

During the excavation with borehole blasting, the effect of multi-borehole blasting is negligible. Thus, the thickness of the blasting excavation disturbance belt was computed using single-borehole blasting with cylindrical charge [6]. To ensure construction safety, the maximum rupture range of the construction was adopted to calculate the maximum value of the stress intensity factor. The calculation formulas can be expressed as:

$$
\begin{aligned}
& K^{\prime}=\sigma_{1} \sqrt{\pi \alpha} f\left(\beta, \theta_{0}\right) \\
& \sigma_{1}=\sigma_{0} /(\bar{R})^{\alpha}
\end{aligned}
$$

where $\bar{R}$ is the proportional distance; $\alpha$ is the reduction factor of the radial direction of the charge under the explosion condition; $\sigma_{0}$ is the initial pulse pressure on the wall of the blasthole (the value depends on the charge structure). Substituting (2) into the crack arrest condition $\left(K_{I}^{\prime} \geq K_{I D}\right)$ of the surrounding rock under the tensile shear stress state, the maximum rupture range $\bar{r}_{\text {max }}$ can be obtained as [15]:

$r_{\max }^{-}=\left[\frac{f_{\max }\left(\beta, \theta_{0}\right) \sqrt{\pi a} \sigma_{0}}{K_{\mathrm{I} D}}\right]^{\frac{1}{a}}$

Then, the thickness of the blasting excavation disturbance belt can be derived with $r_{\max } \approx L_{c}$.

Considering the effect of excavation disturbance, the rock mass on the outside of the GR layer is assumed to have low or no permeability when shear fracturing occurs under high waterhead. In this case, the internal cracks gradually propagate and penetrate through the rock mass, forming a hydraulic fracturing belt with high permeability or no water blocking ability. When the ultimate compressive strength is less than the water pressure, the rock mass will be destroyed from the weak points under the high waterhead [20].

According to the theory on the two belts, the rock mass will fracture when the critical hydraulic pressure of hydraulic fracturing failure is smaller than the external water pressure. The failure conditions can be expressed as:

$$
\begin{aligned}
& P_{c}=\frac{\sigma_{1}+\sigma_{3}}{2}-\frac{\sigma_{1}-\sigma_{3}}{2} \cos 2 \beta- \\
& \frac{1}{f} \times\left(\frac{\left|\sigma_{1}-\sigma_{3}\right|}{2} \sin 2 \beta+\tau_{1}\left|K_{\mathrm{II}}^{(2)}\right|-\frac{\sqrt{3} K_{\mathrm{IIC}}}{2 \sqrt{\pi a}}-c\right)
\end{aligned}
$$

Assuming that the tunnel section is being excavated at the same depth, it can be seen from the above equation that the change of the critical water pressure $P_{c}$ mainly depends on the pressure coefficient and the dynamic stress intensity factor. However, the borehole blasting will unload the blasting excavation disturbance belt. Taking the pressure coefficient as 1 , the critical water pressure of the failure caused by crack propagation can be derived from the above formula as:

$P_{\mathrm{lj}}=\sigma_{1}-\frac{1}{f}\left(\tau_{1}\left|K_{\mathrm{II}}^{(2)}\right|-\frac{\sqrt{3} K_{\mathrm{IIC}}}{2 \sqrt{\pi a}}-c\right)$

If the upper water pressure is greater than the said critical water pressure $\left(P_{w}>P_{l j}\right)$, see Eq.7:

If the upper water pressure is smaller than the said critical water pressure $\left(P_{w}<P_{l j}\right)$, see Eq.8: 
$L_{w}=\frac{11 R}{17}\left\{\ln \lambda-\ln \left[\lambda-\frac{2 f P_{w} \sqrt{\pi a}-\sqrt{3} K_{\mathrm{IIC}}-2 c \sqrt{\pi a}+2 \tau_{1}\left|K_{\mathrm{II}}^{(2)}\right| \sqrt{\pi a}}{\gamma H \sqrt{\pi a}(f-f \cos 2 \beta-\sin 2 \beta)}\right]-\frac{f+f \cos 2 \beta+\sin 2 \beta}{f-f \cos 2 \beta-\sin 2 \beta}\right\}$

$L_{w}=\frac{11 R}{17}\left\{\ln \lambda-\ln \left[\lambda-\frac{2 f P_{w} \sqrt{\pi a}-\sqrt{3} K_{\mathrm{IIC}}-2 c \sqrt{\pi a}+2 \tau_{1}\left|K_{\mathrm{II}}^{(2)}\right| \sqrt{\pi a}}{\gamma H \sqrt{\pi a}(f-f \cos 2 \beta+\sin 2 \beta)}\right]-\frac{f+f \cos 2 \beta-\sin 2 \beta}{f-f \cos 2 \beta+\sin 2 \beta}\right\}$

where $\sigma_{1}=\lambda \sigma_{3}=\lambda \gamma H$ (the units should be unified while computing the $L_{w}$ ).

To sum up, the MST against the hydraulic fracturing failure of the GR layer under high waterhead can be defined as:

$$
L=L_{c}+L_{w}
$$

\subsection{Overall instability}

During the overall instability failure, there is no local stress concentration in the GR layer. In this case, the MST of the GR layer depends on the overall compressive strength and shear strength. For the ideal GR layer rock mass, the overall instability is mainly induced by the disturbance of blasting excavation, and the main load comes from the rock-water weight above, owing to the absence of obvious seepage.

Inspired by the elastic beam model (Figure 6), the mechanics of the GR layer surrounding rock were assumed as follows [5]:

(1) The GR layer surrounding rock is simplified as a rectangular beam, without considering the arching effect between the tunnel and the surrounding rock. Since the elastic beam model mainly targets the plane strain problem, the unfavorable geological sections are assumed to be atop the tunnel and sufficient long in the axial direction of the tunnel. The minimum length equals the greater one between the tunnel height and the tunnel span.

(2) The surrounding rock is considered as a continuous and uniform isotropic elastomer, which conforms to the theory of small deformation.

(3) The compressive stress from the filling water and the upper rock is simplified as a uniformly distributed force perpendicular to the rock beam.

(4) The blasting vibration is simplified as a uniformly distributed load $P(x, t)$.

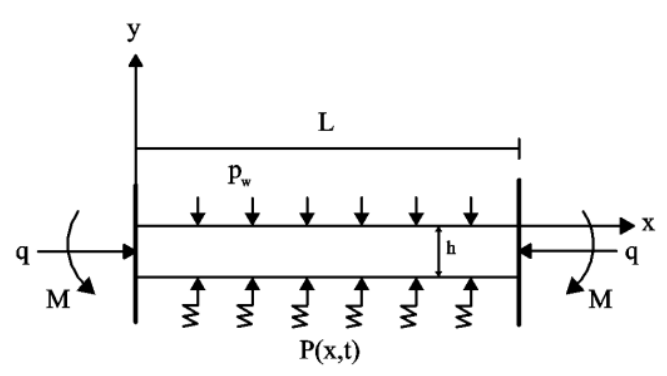

Figure 6. Elastic beam model under dynamic load Note: $p_{w}$ : the stress from the upper water and rock; $q$ is the horizontal geo-stress; $L$ is the beam span; $h$ is the beam thickness; $M$ is the moment on the beam cross-section; $P(x, t)$ is the dynamic blasting load on the rock beam.

Then, the mechanical model can be established as follows: The initial deflection of the beam under static load: $\omega_{0}(x)=\frac{4 H_{0} x}{L^{2}}(L-x)$

The total load on the rock beam:

$q(x, t)=F_{0} \sin (\pi x / L)+P \cos \Omega \sin (\pi x / L)$

where $\sin \left(\frac{\pi x}{t}\right)$ is the deformation modulus of the beam [17]; $F_{0} \sin \left(\frac{\pi x}{L}\right)$ is the vertical static load of the beam; $P \cos \Omega t \sin \left(\frac{\pi x}{L}\right)$ is the stress harmonic load; $F_{0} \approx V=$ $-\left(p_{w}+\rho g l h\right) ; \Omega$ and $P$ are the angular frequency and amplitude of the harmonic load, respectively.

The deflection function of the rock beam:

$\omega(x, t)=f(t) \sin (\pi x / L)$

Considering the linear damping, the vibration of the rock beam can be derived as:

$\ddot{f}+k_{0} \dot{f}+p_{0} f+a f^{3}+F_{0}+F \cos \Omega t=0$

According to the catastrophe model [9], the instability criterion of rock beam under blasting load can be obtained as:

$$
\begin{aligned}
& 4\left[16\left(3 k_{0}^{2} \Omega^{2}-p^{2}\right) / 27 a^{2}\right]+ \\
& 27\left\{16\left[8 p\left(p^{2}+9 k_{0}^{2} \Omega^{2}\right)+81 a F^{2}\right] / 729 a^{3}\right\}^{2}=0
\end{aligned}
$$

The above equation can be expanded as:

$81^{2} F^{4} a^{2}+162 r F^{2}+r^{2}+s=0$

where

$$
\begin{aligned}
& r=8 p\left(p^{2}+9 k_{0}^{2} \Omega^{2}\right) \\
& s=-64\left(3 k_{0}^{2} \Omega^{2}-p^{2}\right)^{3}>0
\end{aligned}
$$

Then, the MST under dynamic load $h_{0}$ can be determined as:

$h_{0}=\frac{4 \rho L^{4}(r+\sqrt{s})}{81 \pi^{4} E b F^{2}}$

The above formula shows that the stability of surrounding rock mainly depends on the weight of the upper rock and the 
horizontal pressure. If the external load remains constant, the overall instability failure is mostly affected by the magnitude of the dynamic blasting load. The failure will occur once the blasting disturbance reaches a certain value. To ensure construction safety, the blasting disturbance should be controlled in the horizontal tunnel sections.

\section{EXAMPLE VERIFICATION}

To verify its rationality, the MST formula was applied to model a section of the weathered trough $\mathrm{F} 4$, section $\mathrm{A} 1$ in Xiamen Xiang'an Subsea Tunnel on the finite-difference software FLAC ${ }^{3 \mathrm{D}}$. The horizontal length of the model was set to $50 \mathrm{~m}$ according to the engineering needs. The tunnel diameter was set to $6.0 \mathrm{~m}$ and the water depth to $12 \mathrm{~m}$. The surrounding rock was considered as grade IV. In light of the geological conditions, the MST against hydraulic fracturing was computed as $3.17 \mathrm{~m}$ and substituted into the established model.

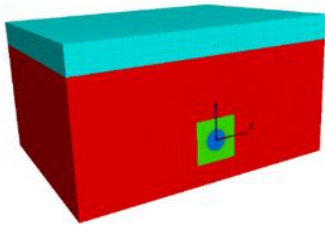

Figure 7. Grid model
The blasting parameters and rock mechanics parameters are respectively provided in Tables 1 and 2 . These parameters were adopted for FLAC $^{3 \mathrm{D}}$ simulation under the following assumptions [18]:

(1) The blasting load is assumed as a compressive stress directly acting on the tunnel wall. During computation, the blasting load can be simplified as an exponential curve.

(2) The loading, unloading and total computation respectively last $12 \mathrm{~ms}, 80 \mathrm{~ms}$ and $>100 \mathrm{~ms}$.

(3) The blasting model is expressed as:

$P(t)=P_{b} f(t)$

where $P_{b}$ is the pulse peak; $f(t)$ is an exponential time lag function.

(4) The maximum peak pressure of exponential wave can be calculated as:

$$
P_{\max }=\frac{139.97}{Z}+\frac{844.81}{Z^{2}}+\frac{2154}{Z^{3}}-0.8034
$$

where $\mathrm{Z}$ is the proportional distance, i.e. the ratio of borehole diameter to the borehole interval.

Table 1. Parameters of borehole blasting

\begin{tabular}{ccccccc}
\hline $\begin{array}{c}\text { Cyclic footage } \\
(\mathrm{m})\end{array}$ & $\begin{array}{c}\text { Equivalent cartridge } \\
\text { diameter }(\mathrm{m})\end{array}$ & $\begin{array}{c}\text { Borehole diameter } \\
(\mathrm{m})\end{array}$ & $\begin{array}{c}\text { Longitudinal wave velocity } \\
(\mathrm{m} / \mathrm{s})\end{array}$ & $\begin{array}{c}\mathrm{m} \\
\mathrm{n}\end{array}$ & $\begin{array}{c}\text { Charge density } \\
\left(\mathrm{g} / \mathrm{cm}^{3}\right)\end{array}$ \\
\hline 2 & 0.35 & 0.42 & 4223 & 0.035 & 0.055 & 1.0 \\
\hline
\end{tabular}

Note: $\mathrm{m}$ and $\mathrm{n}$ are damping parameters.

Table 2. Parameters of rock mechanics

\begin{tabular}{|c|c|c|c|c|c|}
\hline $\begin{array}{c}\text { Grade of surrounding } \\
\text { rock } \\
\end{array}$ & $\begin{array}{c}\text { Elastic modulus } \\
(\mathrm{GPa})\end{array}$ & $\begin{array}{c}\text { Volume weight } \\
\left(\mathrm{kN} / \mathrm{m}^{3}\right)\end{array}$ & $\begin{array}{l}\text { Poisson's } \\
\text { ratio } \\
\end{array}$ & $\begin{array}{c}\text { Internal friction angle } \\
(\% / \mathrm{rad})\end{array}$ & $\begin{array}{c}\text { Cohesion } \\
(\mathrm{MPa})\end{array}$ \\
\hline $\begin{array}{c}\mathrm{V} \\
\text { (Faulty surrounding } \\
\text { rock) }\end{array}$ & 1.1 & 18.5 & 0.45 & $26 / 0.453$ & 0.18 \\
\hline $\begin{array}{c}\text { IV } \\
\text { (Common surrounding } \\
\text { rock) }\end{array}$ & 4.7 & 21.5 & 0.3 & $34 / 0.593$ & 0.42 \\
\hline
\end{tabular}

The calculated MST was imported to the FLAC ${ }^{3 \mathrm{D}}$ for simulation. The cloud map of the plastic zone variation under blasting excavation before and after advanced grouting was obtained (Figure 8).

As shown in Figure 8, the upper rock mass suffered from severe plastic damage under blasting construction after grouting. This is because the upper GR rock mass is severely tensioned and sheared under the repeated disturbance of blasting excavation. As for the post-blasting plastic zone of the GR layer, the maximum plastic deformation appeared in the upper portion of the GR layer side of the tunnel. The deformation thickness was half the tunnel diameter, which is smaller than the theoretical value of $3.17 \mathrm{~m}$. Thus, the MST formula is proved valid.

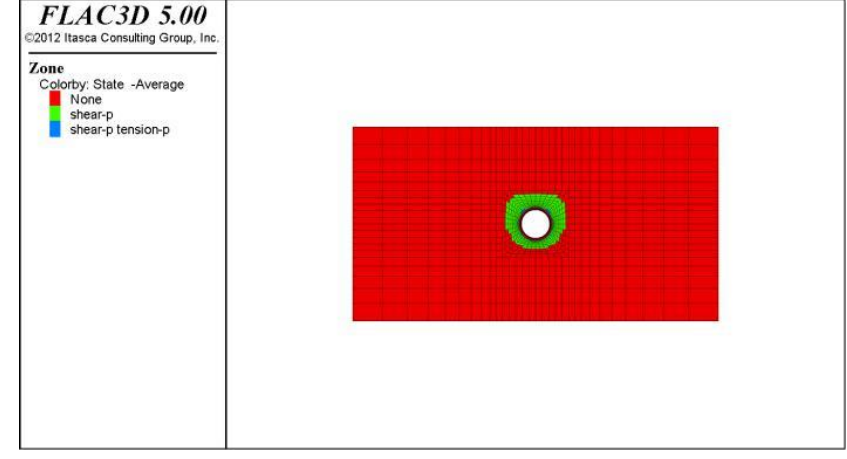

Figure 8. Distribution of plastic zone 


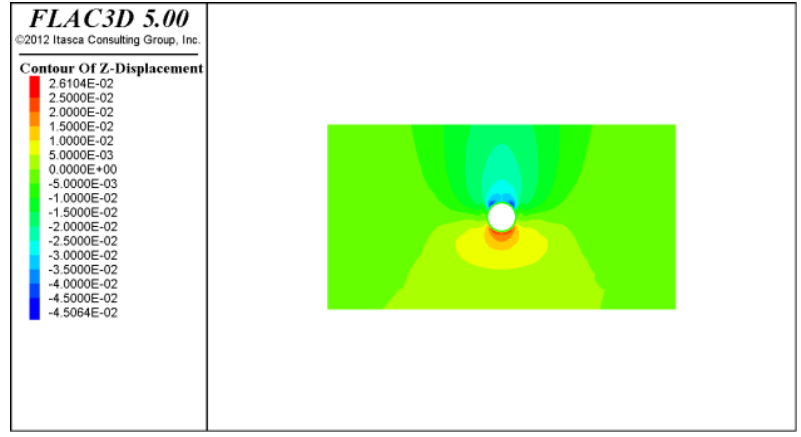

Figure 9. Vertical displacement

As shown in Figure 9, the vertical displacement was symmetrically distributed along the central axis of the tunnel on the roof and bottom. The roof was subjected to the maximum settlement displacement $(4.5 \mathrm{~cm})$ on both sides, while the bottom was slightly heaved by $2 \mathrm{~cm}$. The roof displacement was greater than the bottom displacement, owing to the relatively large scope of plastic zone above the GR layer surrounding rock, plus the rock-water pressure.

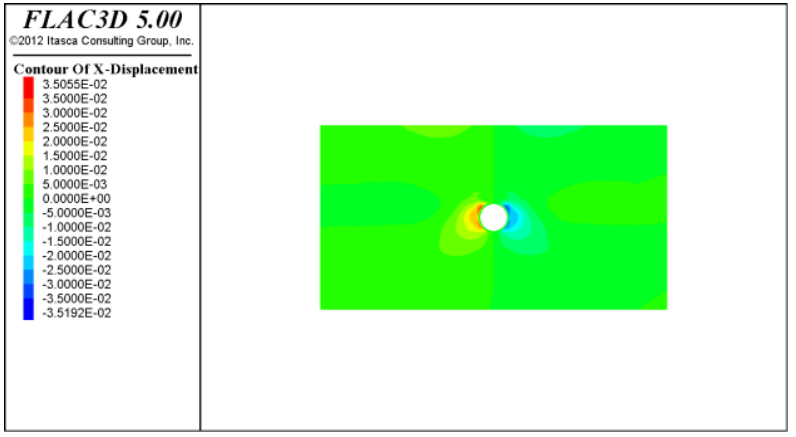

Figure 10. Horizontal displacement

As shown in Figure 10, the horizontal displacement was symmetrically distributed along the central axis of the tunnel on both sides. The two sides were not severely affected, as the construction disturbance concentrated more on the roof. Thus, the horizontal displacement peaked at $3.0 \mathrm{~cm}$ and mainly occurred on the upper part of the tunnel. After all, the deformation is positively correlated with the closeness to the maximum plastic zone.

In the example verification, the MST derived from the proposed formula was inputted to $\mathrm{FLAC}^{3 \mathrm{D}}$ for simulation, which reveals how the plasticity of the GR layer varied under blasting construction. The resulting cloud maps show that the plastic zone fell within the MST and changed consistently with the theoretical result on blasting construction. Moreover, the vertical and horizontal displacements were both within the allowed safe range. Hence, the MST formula was confirmed theoretically as feasible and universal.

\section{CONCLUSIONS}

After summing up tunnel engineering examples, this paper establishes a model on the GR layer according to the theory on GR ring closure. It is confirmed that the GR layer should be grouted into a closed, dense wall around the tunnel, ensuring the safety of subsequent constructions.

The instability mechanism of the GR ring under borehole blasting was analyzed under different geological conditions.
On this basis, the GR layer quality and the external pressure were found to be the keys to instability. Thus, the failure modes were categorized into hydraulic fracturing and overall instability. In hydraulic fracturing mode, the structure losses stability as the cracks from the weakly grouted zone continue to propagate and coalescent, before reaching the yield strength. In the overall instability mode, the GR layer rock mass is damaged by compressive shearing when its yield strength is surpassed by the compressive stress from the upper rock mass.

The two belts models and elastic beam mechanical model were set up for the two failure modes, and used to derive the formulas for the decisive factors of failure, i.e. the MST formulas for the GR layer.

The proposed formula was verified through the simulation of the service tunnel of Xiamen Xiang'an Subsea Tunnel. First, the MST formula was selected according to the geological conditions of the tunnel, and the MST was theoretically computed. On this basis, a numerical simulation was carried out on FLAC ${ }^{3 \mathrm{D}}$, and the elastic, plastic and displacement variations were discussed under the theoretical MST. Finally, the proposed formula was proved rational and universal.

\section{ACKNOWLEDGEMENTS}

This work is supported by Natural Foundation of Shandong Province, China [Grant No. ZR2017MEE069]. Thanks for the support of Natural Foundation of Shandong Province.

\section{REFERENCES}

[1] Li L, Lei T, Li S. (2015). Risk assessment of water inrush in karst tunnels and software development. Arabian Journal of Geosciences 8(4): 1843-1854. https://doi.org/10.1007/s12517-014-1365-3

[2] Li L, Zhou ZQ, Li SC. (2015). An attribute synthetic evaluation system for risk assessment of floor water inrush in coal mines. Mine Water and the Environment 34(3): 288-294. https://doi.org/10.1007/s10230-0140318-0

[3] Luo XW, He FL. (2014). A study of geological structures inclined to disaster and models of water burst in deepburied long tunnels. Modern Tunnelling Technology 51(1): 21-25, 53. https://doi.org/10.13807/j.cnki.mtt.2014.01.006

[4] Li SC, Wang K, Li LP. (2017). Mechanical mechanism and development trend of water-inrush disasters in karst tunnels. Chinese Journal of Theoretical and Applied Mechanics 49(1): 22-30. https://doi.org/10.6052/04591879-16-345

[5] Guo JQ. (2011). Study on against-inrush thickness and water burst mechanism of karst tunnel. Beijing Jiaotong University.

[6] Kuzentsov SV, Troflmov VA. (2002). Hydrodynamic effect of coal seam compression. Journal of Mining Science 39(3): https://doi.org/10.1023/A:1021981716467

[7] Li SC, Yuan YC, Li LP. (2015). Water inrush mechanism and minimum safe thickness of rock wall of karst tunnel face under blast excavation. Chinese Journal of Geotechnical Engineering 37(2): 313-320. https://doi.org/10.11779/CJGE201502015

[8] Zhang JW, Meng ZH, Zeng Y. (2017). Mechanism of 
water burst in the tunnel near faults in karst area. The Chinese Journal of Geological Hazard and Control 28(3): 73-79. https://doi.org/10.16031/j.cnki.issn.10038035.2017.03.11

[9] Li LP, Li SC, Zhang QS. (2010). Study of mechanism of water inrush induced by hydraulic fracturing in karst tunnels. Rock and Soil Mechanics 31(2): 523-528. https://doi.org/10.16285/j.rsm.2010.02.016

[10] Chi MJ, Zhao CG, Yang XL. (2004). Study on controlling vibration hazard of tunnel cave blasting in karst area. China Safety Science Journal 14(9): 72-75, 2. https://doi.org/10.16265/j.cnki.issn10033033.2004.09.016

[11] Liu Y. (2010). Grouting Technology of Rock Mass in Fractured Zone of Shallow Tunnel. Central South University.

[12] Li SC, Zhang WJ, Zhang QS. (2014). Research on advantage-fracture grouting mechanism and controlled grouting method in water-rich fault zone. Rock and Soil Mechanics 35(3):

744-752. https://doi.org/10.16285/j.rsm.2014.03.030

[13] Li LP, Lu W, Li SC. (2010). Research status and developing trend analysis of the water inrush mechanism for underground engineering construction. Journal of Shandong University (Engineering Science) 40(3): 104$112,118$.

[14] Chen J, Wei YS, Jiang H. (2017). Causes analysis and countermeasures for water inrush and sand gushing in fault and fracture zone during mined metro tunnel excavation. Tunnel Construction 37(7): 857-863. https://doi.org/10.3973/j.issn.1672-741X.2017.07.012

[15] Liu YS, Peng L, Wang MS. (2015). Blast-induced fractured zone of fractured rock-mass tunnel. China Journal of Highway and Transport 28(10): 83-89. https://doi.org/10.19721/j.cnki.1001-7372.2015.10.011

[16] Lu WB, Hustrulid W. (2003). Design approach for excavation blasting near contour of rock slope. Chinese Journal of Rock Mechanics and Engineering 22(12): 2052-2056.

https://doi.org/10.1142/S0252959903000104
[17] Li YZ, Li ZG, Wang QS. (2013). On the grouting reinforcement and waterproofing techniques for mined subsea tunnels in soft fractured strata. Tunnel $\begin{array}{lll}\text { Construction } & 50(2) \text { : }\end{array}$ https://doi.org/10.13807/j.cnki.mtt.2013.02.010

[18] Zhang X, Li SC. (2007). Stability analysis of rock cover of Qingdao Kiaochow bay sub-sea tunnel under explosive loads. Chinese Journal of Rock Mechanics and Engineering 26(11): 2348-2355.

[19] Li XY, Zhang DL, Fang Q. (2015). On water burst patterns in underwater tunnels. Modern Tunnelling Technology 52(04): $\quad$ 24-31, 40 https://doi.org/10.13807/j.cnki.mtt.2015.04.004

[20] Huang RQ, Wang XN, Chen LS. (2000). Hydro-splitting off analysis on underground water in deep-lying tunnels and its effect on water gushing out. Chinese Journal of Rock Mechanics and Engineering 19(5): 573-576.

[21] Berta G. (1994). Blasting-induced vibration in tunnelling. Tunneling and Underground Space Technology 9(2): 175-187. https://doi.org/10.1016/0886-7798(94)90029-9

[22] Sakural S, Kitamura Y. (1977). Vibration of tunnel due to adjacent blasting operation. Proceedings of International Symposium on Field Measurements in Rock Mechanics 61-74.

[23] Dai CQ, Zhao ZH. (2018). Survey on rheological behaviour of weakly cemented soft rock considering water deterioration. Journal of Advanced Oxidation

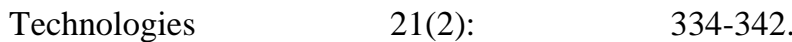
https://doi.org/10.26802/jaots.2018.01824

[24] Dai CQ, Zhao ZH. (2015). Fuzzy comprehensive evaluation model for construction risk analysis in urban subway. International Journal of Modeling, Simulation, and Scientific Computing 6(3): 11-17. https://doi.org/10.1142/S1793962315500245

[25] Dai CQ, Lv YL. (2018). A novel image enhancement technique for tunnel leakage image detection. Tunnel Leakage Image Detection Technique 35: 209-222. https://doi.org/10.3166/TS.35.209-222 